\title{
Preoperative Platelet-to-Albumin Ratio Predicts Prognosis of Patients with Pancreatic Ductal Adenocarcinoma After Pancreatic Resection
}

\author{
YOSHIHIRO SHIRAI ${ }^{1,2}$, HIROAKI SHIBA $^{1}$, KOICHIRO HARUKI $^{1}$, TAKASHI HORIUCHI ${ }^{1,2}$, NOBUHIRO SAITO ${ }^{1,2}$, \\ YUKI FUJIWARA $^{1}$, TARO SAKAMOTO ${ }^{1}$, TADASHI UWAGAWA ${ }^{1,3}$ and KATSUHIKO YANAGA ${ }^{1}$ \\ ${ }^{1}$ Department of Surgery, ${ }^{2}$ Division of Gene Therapy, Research Center for Medical Sciences, and \\ ${ }^{3}$ Division of Clinical Oncology and Hematology, Department of Internal Medicine, \\ The Jikei University School of Medicine, Tokyo, Japan
}

\begin{abstract}
Background: The aim of this study was to evaluate a novel prognostic value of preoperative platelet-to-albumin ratio (PAR) in patients resected for pancreatic cancer. Patients and Methods: A total of 107 patients who underwent pancreatic resection for pancreatic cancer were studied. The patients were divided into two groups as $P A R \geq 46.4 \times 10^{3}$ or $<46.4 \times 10^{3}$. Survival data were analyzed using the log-rank test for univariate analysis and Cox proportional hazards for multivariate analysis. Results: The PAR was a significant prognostic index on univariate analysis for disease-free survival (DFS) and overall survival (OS). The PAR retained its significance on multivariate analysis for OS (hazard ratio $(H R)=2.344,95 \%$ confidence interval $(C I)=1.188-4.624$, $p=0.014$ ) along with tumor differentiation and nodal involvement. PAR was a significant independent prognostic index for poor DFS on multivariate analysis $(H R=1.971$, 95\% CI=1.128-3.444, $\quad p=0.017)$. Conclusion: The preoperative $P A R$ is a novel significant independent prognostic index for DFS and OS in patients after pancreatic resection with curative intent.
\end{abstract}

Pancreatic ductal adenocarcinoma (PDAC) is one of the most aggressive types of cancer and fourth leading cause of cancer related death in developed countries (1), for which pancreatic resection is the only potentially cure treatment, but prognosis after surgical resection remains unsatisfactory. The median survival time after pancreatic resection with curative intent

Correspondence to: Yoshihiro Shirai, MD, Ph.D., The Jikei University School of Medicine, 3-25-8, Nishi-Shinbashi, Minatoku, Tokyo 105-8461, Japan. Tel: +81 334331111 ext. 3401, Fax: +81334331230, e-mail: shirai@jikei.ac.jp

Key Words: Platelet to albumin ratio, pancreatic cancer, prognostic index, pancreatic resection, PAR, inflammation. and adjuvant chemotherapy is reported to be only 20-23.6 months (2). Currently, several clinical phase II or III clinical trials including neoadjuvant or adjuvant chemotherapy, immunotherapy or molecular target therapy are ongoing (3). In order to select a relevant therapeutic strategy, preoperative evaluation of cancer prognosis is important.

Recently, it has been recognized that systemic inflammation plays a crucial role in carcinogenesis, tumor progression and metastasis (4). A number of reports demonstrated a correlation between postoperative prognosis and systemic inflammation-based prognostic score, including the Glasgow Prognostic Score (GPS) (5), modified Glasgow Prognostic Score (mGPS) (6), neutrophil-to-lymphocyte ratio (NLR) (7), platelet-to-lymphocyte ratio (PLR) (8), Prognostic Nutrition Index (PNI) (9), and C-reactive protein to albumin ratio (CAR) (10). However, the relation between these prognostic scores and therapeutic outcomes in PDAC are still controversial (11). Preoperative platelet count and serum albumin level are correlated with cancer progression, but to our knowledge there are no reports about any index including both platelet counts and serum albumin level in any type of cancer. Herein we demonstrate the prognostic value of the platelet-to-albumin ratio (PAR), a novel inflammation-based prognostic score, and compared PAR with several existing prognostic scores in patients with PDAC after pancreatic resection with curative intent.

\section{Patients and Methods}

Between 2003 and 2013, 121 patients with PDAC underwent pancreatic resection with curative intent at the Department of Surgery, Jikei University Hospital, Tokyo, Japan. We performed a retrospective review of a prospectively maintained database of patients who were histologically diagnosed with PDAC. Patients were excluded as follows: eight were lost to follow-up, one died in hospital, five died from other causes and one committed suicide. A total of 107 patients were therefore studied. This research was approved by the Ethics 
Committee of The Jikei University School of Medicine [approval number: 27-177 (8062)]. The detailed pathological factors were based on the seventh edition of the UICC TNM Classification (12). All excised specimens were diagnosed at the Department of Pathology, Jikei University Hospital, Tokyo, Japan. The laboratory data immediately before surgery were evaluated. All borderline cases underwent surgery without neoadjuvant chemotherapy.

We investigated the relation between clinicopathological variables and disease-free (DFS) as well as overall survival (OS) after curative pancreatic resection by univariate and multivariate analyses. The GPS was constructed as previously described (5). NLR (7), PLR (8), PNI (9) and CAR (10) were calculated on the basis of previous studies. PAR was calculated as the platelet count divided by serum albumin level. The cut-off values of these inflammation-based prognostic scores were classified into two groups for the log-rank test and Cox proportional regression model on the basis of receiver operating characteristic (ROC) curve analysis using 5 -year survival, except for those using a fixed cutoff value i.e. the GPS and PNI.

We analyzed the relationship between clinicopathological variables including inflammation-based prognostic scores and survival after pancreatic resection for PDAC by univariate and multivariate analysis of 17 factors: tumor stage, tumor size, tumor differentiation, nodal involvement, resection margin status, preoperative biliary drainage, operation type, operation time, estimated blood loss, adjuvant chemotherapy, serum carbohydrate antigen 19-9 (CA19-9), GPS, NLR, PLR, PNI, CAR, and PAR. Next, we investigated the relation between PAR and clinicopathological variables by univariate analysis.

Recurrence of PDAC was defined as local or distant metastatic tumors newly detected by ultrasonogaphy, computed tomography, or magnetic resonance image with or without increase in serum CA19-9.

Statistical analysis. Continuous variables are expressed as median and interquartile range. Categorical variables were expressed as absolute numbers. Univariate analyses for categorical data were performed using Chi-square tests. The OS and DFS rates were calculated by Kaplan-Meier method. Comparisons of DFS and OS were performed using the log-rank test for univariate analysis, and the Cox proportional regression model with backward elimination stepwise approach for multivariate analysis. The area under the ROC curve (AUC) were calculated to determine the cut-off value for each prognostic score. $p$-Values were considered statistically significant when less than 0.05 .

\section{Results}

Patient characteristics. Table I lists patient characteristics. Among the study population, the median age was 68 years ( 25 to 75 percentile of 61-74 years), and 62 of them were male. Eighty-eight percent of patients had stage II or III PDAC. Median OS and DFS after pancreatic resection with curative intent for PDAC were 23.7 and 11.5 months, and 5year survival rates were $22.6 \%$ and $17.1 \%$, respectively.

Relationship between clinical variables and OS. The relationship between clinicopathological variables including inflammation-based prognostic scores and OS after
Table I. Patient characteristics $(n=107)$.

\begin{tabular}{lcc}
\hline Factor & Value & Range (IQR) \\
\hline Age (years) & 68 & $61-74$ \\
Gender, male: female & $62: 45$ & \\
Tumor stage, I: II, III & $13: 94$ & \\
Disease-free survival (months) & $11.5^{*}$ & $7.7-15.4^{* *}$ \\
Overall survival $(\mathrm{months})$ & $23.7^{*}$ & $16.0-31.5^{* *}$ \\
White blood cell count $\left(\times 10^{3} / \mathrm{ml}\right)$ & 5.5 & $4.5-6.6$ \\
Neutrophil count $\left(\times 10^{3} / \mathrm{ml}\right)$ & 3.2 & $2.5-4.2$ \\
Lymphocyte count $\left(\times 10^{3} / \mathrm{ml}\right)$ & 1.5 & $1.1-1.8$ \\
Platelet count $\left(\times 10^{3} / \mathrm{ml}^{2}\right)$ & 224 & $179-260$ \\
Serum albumin $(\mathrm{g} / \mathrm{dl})$ & 3.9 & $3.5-4.1$ \\
Serum CRP $(\mathrm{mg} / \mathrm{l})$ & 1.1 & $0.5-3.7$ \\
Serum CA19-9 $(\mathrm{U} / \mathrm{ml})^{* * *}$ & 99.5 & $27-341$ \\
PLR & 151.3 & $115.5-190.9$ \\
NLR & 2.1 & $1.6-3.0$ \\
PNI & 46.0 & $42.0-49.5$ \\
CAR & 0.03 & $0.01-0.11$ \\
PAR $\left(\times 10^{3}\right)$ & 57.1 & $46.1-72.5$ \\
\hline
\end{tabular}

IQR: Interquartile range; BMI: body mass index; CRP: C-reactive protein; CA19-9: carbohydrate antigen 19-9; PLR: platelet to lymphocyte ratio; NLR: neutrophil-to-lymphocyte ratio; GPS: Glasgow Prognostic Score; PNI: prognostic nutritional index; CAR: CRP-toalbumin ratio; PAR: platelet-to-albumin ratio; *median survival time; **95\% confidence interval; ***data for 104 patients.

pancreatic resection for PDAC are shown in Table II. In univariate analysis, tumor stage $(p=0.007)$, tumor size $(p=0.009)$, tumor differentiation $(p<0.001)$, nodal involvement $(p<0.001)$, preoperative biliary drainage $(p=0.002)$, serum CA19-9 $(p=0.001), \operatorname{PLR}(p=0.048)$, CAR $(p=0.009)$, and PAR $(p=0.001)$ were significant prognostic factors of poor patient survival. In multivariate analysis, tumor differentiation $(p<0.001)$, nodal involvement $(p=0.001)$, and PAR $(p=0.014)$ were independent risk factors of poor patient survival. ROC curves were calculated for survival status at 5-year follow-up, and the AUC values were compared to assess cut-offs for each prognostic score as independent risk factors (Table III). The PAR had the highest AUC value $(0.690 \pm 0.06, p=0.002)$ compared to the other prognostic scores as independent risk factors (Figure 1).

Relationship between clinical variables and DFS. The relationship between clinical variables and DFS are shown in Table IV. In multivariate analysis, tumor stage $(p=0.043)$, tumor differentiation $(p=0.002)$, nodal involvement $(p<0.001)$, preoperative biliary drainage $(p=0.029)$, serum CA19-9 $(p=0.009)$, and PAR ( $p=0.003)$ were significant risk factor for cancer recurrence. In multivariate analysis, tumor differentiation $(p<0.001)$, nodal involvement $(p=0.002)$, and PAR $(p=0.017)$ remained independent risk factors for cancer recurrence. 
Table II. Univariate and multivariate analyses of clinicopathological variables in relation to overall survival.

\begin{tabular}{|c|c|c|c|c|c|c|}
\hline \multirow[b]{2}{*}{ Factor } & \multirow[b]{2}{*}{ Comparison } & \multirow[b]{2}{*}{$\mathrm{N}=107$} & \multicolumn{2}{|c|}{ Univariate analysis } & \multicolumn{2}{|c|}{ Multivariate analysis } \\
\hline & & & $\mathrm{HR}(95 \% \mathrm{CI})$ & $p$-Value & $\mathrm{HR}(95 \% \mathrm{CI})$ & $p$-Value \\
\hline Tumor stage & II, III vs. I & $94 / 13$ & $3.193(1.245-3.977)$ & 0.007 & & n.s \\
\hline Tumor size & $\geq 40 \mathrm{vs} .<40 \mathrm{~mm}$ & $39 / 68$ & $1.811(1.191-3.186)$ & 0.009 & & n.s \\
\hline \multirow[t]{3}{*}{ Tumor differentiation } & Poor & 12 & $3.495(2.541-22.19)$ & $<0.001$ & $2.563(1.739-3.778)$ & $<0.001$ \\
\hline & Moderate & 55 & $2.554(1.599-4.213)$ & & & \\
\hline & Well & 40 & Referent & & & \\
\hline Nodal involvement & Positive $v s$. negative & $71 / 36$ & $2.434(1.435-3.589)$ & $<0.001$ & $2.389(1.337-4.267)$ & 0.001 \\
\hline Resection margin status & Positive $v s$. negative & $31 / 76$ & $1.419(0.875-2.455)$ & 0.148 & & $\mathrm{n} . \mathrm{s}$ \\
\hline Preoperative biliary drainage & Positive $v s$. negative & $42 / 65$ & $1.977(1.343-3.616)$ & 0.002 & & n.s \\
\hline Operation & PD: DP: TP & $73: 31: 3$ & & 0.438 & & n.s \\
\hline Operative time & $\geq 524$ vs. $<524 \mathrm{~min}$ & $47 / 60$ & $1.335(0.856-2.133)$ & 0.201 & & n.s \\
\hline Estimated blood loss & $\geq 455$ vs. $<455 \mathrm{ml}$ & $82 / 25$ & $1.699(0.970-2.649)$ & 0.068 & & n.s \\
\hline Adjuvant chemotherapy & Negative $v s$. positive & $17 / 88$ & $1.133(0.599-2.174)$ & 0.690 & & n.s \\
\hline Serum CA19-9* & $\geq 316.5 \mathrm{vs} .<316.5 \mathrm{U} / \mathrm{ml}$ & $28 / 76$ & $2.207(1.571-5.165)$ & 0.001 & & $\mathrm{n} . \mathrm{s}$ \\
\hline GPS & 1,2 vs. 0 & $31 / 76$ & $1.415(0.869-2.469)$ & 0.154 & & $\mathrm{n} . \mathrm{s}$ \\
\hline NLR & $\geq 1.58$ vs. $<1.58$ & $79 / 28$ & $1.414(0.868-2.276)$ & 0.177 & & $\mathrm{n} . \mathrm{s}$ \\
\hline PLR & $\geq 143$ vs. $<143$ & $45 / 62$ & $1.575(1.014-2.493)$ & 0.048 & & n.s \\
\hline PNI & $\leq 45$ vs. $>45$ & $45 / 62$ & $1.238(0.787-1.986)$ & 0.349 & & n.s \\
\hline CAR & $\geq 0.032$ vs. $>0.032$ & $52 / 55$ & $1.795(1.170-2.908)$ & 0.009 & & $\mathrm{n} . \mathrm{s}$ \\
\hline $\operatorname{PAR}\left(\times 10^{3}\right)$ & $\geq 46.4$ vs. $<46.4$ & $80 / 27$ & $2.810(1.405-3.678)$ & 0.001 & $2.344(1.188-4.624)$ & 0.014 \\
\hline
\end{tabular}

HR: Hazard ratio; CI: confidence interval; PD: pancreatoduodenectomy; DP: distal pancreatectomy; TP: total pancreatectomy; CA19-9: carbohydrate antigen 19-9; GPS: Glasgow Prognostic Score; NLR: neutrophil-to-lymphocyte ratio; PLR: platelet-to-lymphocyte ratio; PNI: prognostic nutritional index; CAR: C-reactive protein to albumin ratio; PAR: platelet to albumin ratio; ns: not significant. *Data for 104 patients.

Univariate analysis of clinical variables in relation to PAR. The relationship between clinical variables and status of PAR are shown in Table $\mathrm{V}$. The group with a high PAR $\left(\geq 46.4 \times 10^{3}\right)$ group had larger tumor size $(p=0.025)$, higher frequency of positive nodal involvement $(p=0.005)$, higher frequency of preoperative biliary drainage $(p=0.003)$, higher GPS $(p=0.004)$, higher PLR $(p=0.001)$, and higher CAR $(p<0.001)$.

Relationship between $P A R$ and survival. In univariate analysis, the high PAR $\left(\geq 46.4 \times 10^{3}\right)$ group had poor median DFS (8.4 vs. 23.3 months, $p=0.0032)$ and OS (18.9 vs. 77.7 months, $p=0.0009$ ) compared with the group with low PAR (Figure 2); 5-year OS was $14.7 \%$ and $52.1 \%$, respectively.

\section{Discussion}

Cancer-related inflammation affects cancer initiation, promotion, progression and metastasis (13). Cancer cells produce inflammatory cytokines and growth factors such as interleukin (IL) 1, IL6, IL11, IL23 and tumor necrosis factor- $\alpha$ (14). Indeed, IL1 and IL6 are reported to be elevated in patients with PDAC (15), and these cytokines stimulate megakaryocytes to thrombocytosis (16). The impact of platelets on cancer is divided broadly into two categories as cancer progression or protection from immune surveillance system. Platelets are
Table III. Comparison of the area under the receiver operating characteristic curve (AUC) for different prognostic factors.

\begin{tabular}{lccc}
\hline Factor & AUC & $95 \%$ CI & $p$-Value \\
\hline Tumor differentiation & $0.653 \pm 0.06$ & $0.539-0.767$ & 0.012 \\
Nodal involvement & $0.673 \pm 0.06$ & $0.558-0.788$ & 0.004 \\
PAR & $0.690 \pm 0.06$ & $0.574-0.806$ & 0.002 \\
\hline
\end{tabular}

CI: Confidence interval; PAR: platelet-to-albumin ratio.

actively recruited to tumor cells through tumor cell-induced platelet aggregation, and adhere to tumor cells by several platelet receptors such as P-selectin, glycoprotein (GP) Ib-IX$\mathrm{V}$ and GPIIb/IIIa (17). The recently described P-selectin, an adhesion molecule expressed on the surface of platelets, binds a variety of tumor cells, and mediates association with other inflammatory cells (18). In addition, P-selectin plays a direct role in tumor growth and metastasis (19).

Recruited platelets alter the microenvironment of tumor cells by tumor growth factors, such as vascular endothelial growth factor (VEGF), platelet derived growth factor (PDGF), transforming growth factor- $\beta 1$ (TGF $\beta 1)$, and insulin-like growth factor-1 (IGF1). These growth factors are $\alpha$-granule constituents of platelets and play a crucial role in all stage of 
A

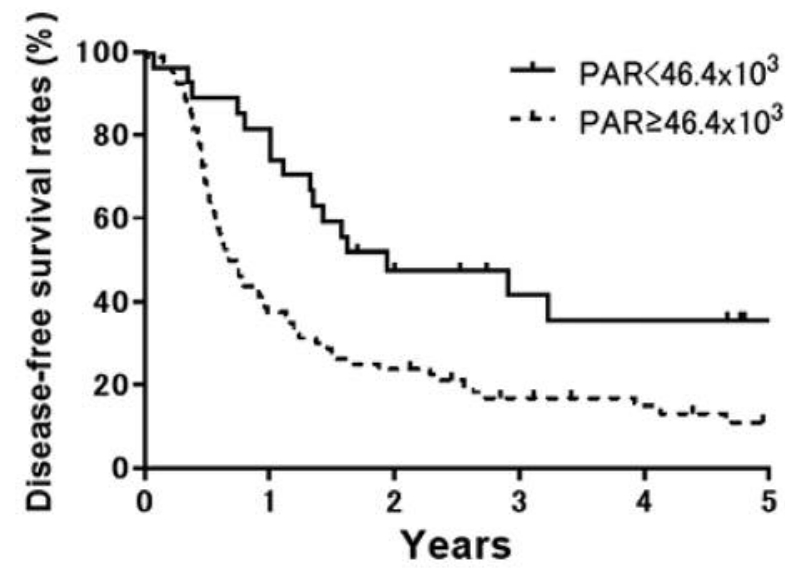

B

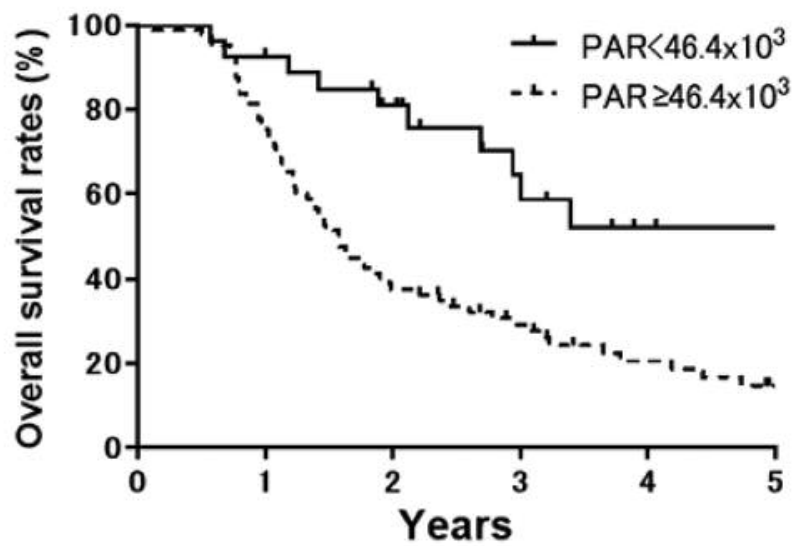

Figure 1. In statistical analysis, platelet to albumin ratio (PAR) of $46.4 \times 10^{3}$ or more was an independent risk factor for poor disease-free survival (median disease-free survival time, $P A R<46.4 \times 10^{3} \mathrm{vs}$. $P A R \geq 46.4 \times 10^{3}=23.3 \mathrm{vs} .8 .5$ months, $p=0.003$ ) (A), and overall survival (median survival time, $P A R<46.4 \times 10^{3}$ vs. $P A R \geq 46.4 \times 10^{3}=77.1$ vs. 19.0 months, $\left.p=0.001\right)(B)$.

Table IV. Univariate and multivariate analysis of clinicopathologic variables in relation to disease-free survival.

\begin{tabular}{|c|c|c|c|c|c|c|}
\hline \multirow[b]{2}{*}{ Factor } & \multirow[b]{2}{*}{ Comparison } & \multirow[b]{2}{*}{$\mathrm{N}=107$} & \multicolumn{2}{|c|}{ Univariate analysis } & \multicolumn{2}{|c|}{ Multivariate analysis } \\
\hline & & & HR $(95 \% \mathrm{CI})$ & $p$-Value & HR $(95 \% \mathrm{CI})$ & $p$-Value \\
\hline Tumor stage & II, III $v s$. I & $94 / 13$ & $2.069(1.022-3.108)$ & 0.043 & & $\mathrm{n} . \mathrm{s}$ \\
\hline Tumor size & $\geq 40 v s .<40 \mathrm{~mm}$ & $39 / 68$ & $1.495(0.981-2.457)$ & 0.064 & & $\mathrm{n} . \mathrm{s}$ \\
\hline \multirow[t]{3}{*}{ Tumor differentiation } & Poor & 12 & $2.453(1.396-8.613)$ & 0.002 & $2.129(1.478-3.065)$ & $<0.001$ \\
\hline & Moderate & 55 & $2.029(1.318-3.260)$ & & & \\
\hline & Well & 40 & Referent & & & \\
\hline Nodal involvement & Positive $v s$. negative & $71 / 36$ & $2.319(1.450-3.386)$ & $<0.001$ & $2.314(1.378-3.886)$ & 0.002 \\
\hline Resection margin status & Positive $v s$. negative & $31 / 76$ & $1.282(0.806-2.106)$ & 0.281 & & $\mathrm{n} . \mathrm{s}$ \\
\hline Preoperative biliary drainage & Positive $v s$. negative & $42 / 65$ & $1.519(1.058-2.614)$ & 0.029 & & n.s \\
\hline Operation & PD: DP: TP & $73: 31: 3$ & & 0.755 & & n.s \\
\hline Operative time & $\geq 524 v s .<524 \mathrm{~min}$ & $47 / 60$ & $1.263(0.828-1.964)$ & 0.275 & & n.s \\
\hline Estimated blood loss & $\geq 455$ vs. $<455 \mathrm{ml}$ & $82 / 25$ & $1.442(0.876-2.254)$ & 0.162 & & $\mathrm{n} . \mathrm{s}$ \\
\hline Adjuvant chemotherapy & Negative $v s$. positive & $17 / 88$ & $0.859(0.485-1.543)$ & 0.624 & & n.s \\
\hline Serum CA19-9* & $\geq 316.5 v s .<316.5 \mathrm{U} / \mathrm{ml}$ & $28 / 76$ & $1.814(1.206-3.530)$ & 0.009 & & n.s \\
\hline GPS & 1,2 vs. 0 & $31 / 76$ & $1.122(0.703-1.804)$ & 0.623 & & $\mathrm{n} . \mathrm{s}$ \\
\hline NLR & $\geq 1.58 \mathrm{vs} .<1.58$ & $79 / 28$ & $1.242(0.772-1.967)$ & 0.384 & & $\mathrm{n} . \mathrm{s}$ \\
\hline PLR & $\geq 143$ vs. $<143$ & $45 / 62$ & & 0.061 & & n.s \\
\hline PNI & $\leq 45$ vs. $>45$ & $45 / 62$ & $1.058(0.690-1.626)$ & 0.795 & & n.s \\
\hline CAR & $\geq 0.032$ vs. $>0.032$ & $52 / 55$ & $1.411(0.930-2.180)$ & 0.106 & & $\mathrm{n} . \mathrm{s}$ \\
\hline PAR $(\times 103)$ & $\geq 46.4 v s .<46.4$ & $80 / 27$ & $2.162(1.258-3.057)$ & 0.003 & $1.971(1.128-3.444)$ & 0.017 \\
\hline
\end{tabular}

HR: Hazard ratio; CI: confidence interval; PD: pancreatoduodenectomy; DP: distal pancreatectomy; TP: total pancreatectomy; CA19-9: carbohydrate antigen 19-9; GPS: Glasgow Prognostic Score; NLR: neutrophil-to-lymphocyte ratio; PLR: platelet-to-lymphocyte ratio; PNI: prognostic nutritional index; CAR: C-reactive protein-to-albumin ratio; PAR: platelet to albumin ratio; ns: not significant. *Data for 104 patients.

cancer progression, including tumorigenesis, angiogenesis, proliferation and metastasis (19). Indeed, the association of these factors and poor survival of patients with PDAC has been clarified (20-22), and these factors are considered valid targets of molecular-targeted therapies (23). Platelets protect tumor cells from the immune system. To transfer to another sites, tumor cells have to go through several steps such as detachment of primary cites, intravasation into vascular as circulating tumor cells (CTCs), extravasation into metastasis sites, and proliferation. CTCs are easily attacked by immune 
Table V. Univariate analysis of clinical variables in relation to preoperative platelet to albumin ratio (PAR).

\begin{tabular}{|c|c|c|c|}
\hline \multirow[t]{2}{*}{ Factor } & \multicolumn{2}{|c|}{ PAR } & \multirow{2}{*}{$\begin{array}{c}p \text {-Value } \\
\text { (univariate) }\end{array}$} \\
\hline & $<46.4 \times 10^{3}(\mathrm{n}=27)$ & $\geq 46.4 \times 10^{3}(\mathrm{n}=80)$ & \\
\hline Tumor stage (I: II, III) & 4: 23 & 9: 71 & 0.624 \\
\hline Tumor size, $<40 \mathrm{~mm}: \geq 40 \mathrm{~mm}$ & 22: 5 & 40: 28 & 0.025 \\
\hline Tumor differentiation, well: moderate: poor & 13: $11: 3$ & 27: $44: 9$ & 0.383 \\
\hline Nodal involvement, negative: positive & 15: 12 & 21: 59 & 0.005 \\
\hline Resection margin status, negative: positive & 21: 6 & $55: 25$ & 0.371 \\
\hline Preoperative biliary drainage, negative: positive & $23: 4$ & 42: 38 & 0.003 \\
\hline Operation, PD: DP: TP & 14: $11: 2$ & 59: $20: 1$ & 0.053 \\
\hline Operative time, $<524 \mathrm{~min}: \geq 524 \mathrm{~min}$ & 15: 12 & 45: 35 & 0.950 \\
\hline Estimated blood loss, $<455 \mathrm{ml}: \geq 455 \mathrm{ml}$ & $6: 21$ & 19: 61 & 0.871 \\
\hline Adjuvant chemotherapy, negative: positive & 4: 23 & 13: 65 & 0.822 \\
\hline Serum CA19-9, $<372: \mathrm{U} / \mathrm{ml} \geq 372 \mathrm{U} / \mathrm{ml}^{*}$ & $22: 5$ & 54: 23 & 0.253 \\
\hline GPS, $0: 1,2$ & $25: 2$ & 51: 29 & 0.004 \\
\hline NLR, $<1.58: \geq 1.58$ & 5: 22 & 23: 57 & 0.296 \\
\hline PLR, $<143: \geq 143$ & 8: 19 & 53: 27 & 0.001 \\
\hline PNI, $\geq 45:<45$ & 19: 8 & 43: 37 & 0.130 \\
\hline CAR $,>0.032: \geq 0.032$ & $22: 5$ & 33: 47 & $<0.001$ \\
\hline
\end{tabular}

CA19-9: Carbohydrate antigen 19-9; GPS: Glasgow Prognostic Score; NLR: neutrophil to lymphocyte ratio; PLR: platelet to lymphocyte ratio; PNI: prognostic nutritional index; CAR: CRP to albumin ratio; *data for 104 patients.

cells such as natural killer (NK) cells, resulting in their death before metastasis. However, in this step, platelets surround CTCs through tumor cell-induced platelet aggregation, allowing escape from $\mathrm{NK}$ cell recognition, and protecting tumor cells from immune attack and physical damage (24). TGF $\beta$ and PDGF derived from platelets directly inhibit function of NK cells by down-regulating expression of natural killer group 2 member D (NKG2D) receptor on NK cells (25), which recognizes tumor-specific antigen MHC class I chainrelated gene A/B $(26,27)$. Furthermore, P-selectin not only mediates between platelets and CTCs (28), but also tethers the tumor cell-platelet complex to the microvascular environment in metastatic sites.

The correlation between hypoalbuminemia and poor patient survival has been reported in several types of cancer (29). Hypoalbuminemia is caused by malnutrition and cachexia in patients with cancer, which reduces their response to treatment and increases the risk of anticancer agent-induced toxicity. Systemic inflammation suppresses albumin synthesis in hepatocytes by production of cytokines such as IL6. In addition, metastatic tumor cells induce Kupffer cells in the liver to produce cytokines, and reduce albumin synthesis (29). Consequential hypoalbuminemia is also correlated with impairment of a variety of immune system functions (30), and helps tumor cell promotion and metastasis as a result.

For these reasons, a prognostic index using the platelet count and serum albumin levels seems to be useful for estimation of cancer prognosis in patients with PDAC.

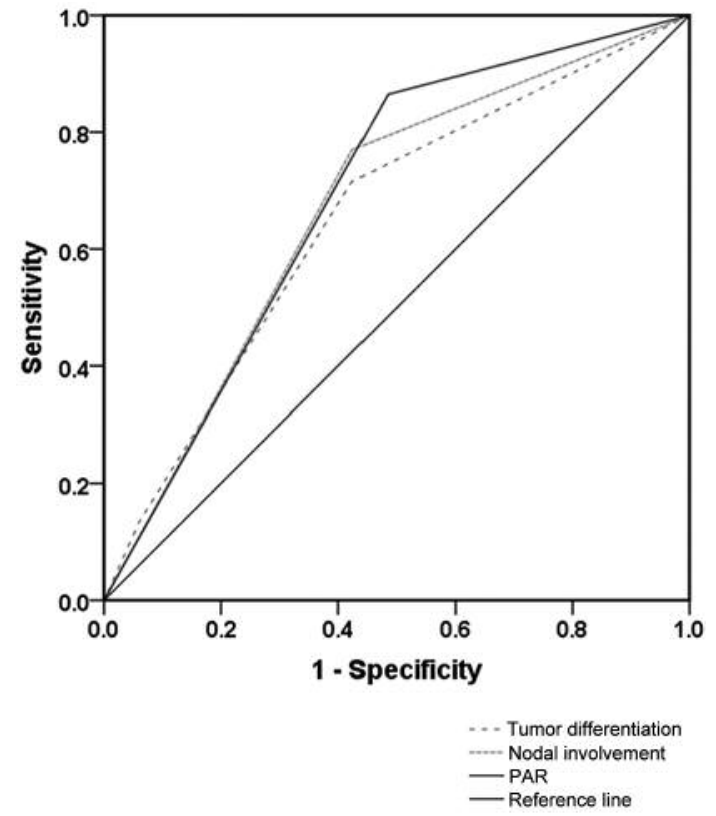

Figure 2. The receiver operating characteristic curve for prediction of 5-year survival by different prognostic factors i.e. tumor differentiation, nodal involvement, and platelet-to-albumin ratio (PAR).

However, as far as we are aware, there has been no report to date on the PAR as an index in any type of cancer. In this study, PAR was a novel significant prognostic factor of poor patient survival in univariate and multivariate analyses, 
together with tumor differentiation and nodal involvement. Furthermore, PAR had a higher AUC value compared to tumor differentiation and nodal involvement. The measurements of platelet count and serum albumin level are included in routine preoperative evaluation, and all patients who undergo pancreatic resection for PDAC can be examined before surgery. Accordingly, PAR is a very simple tool for estimating the prognosis of patients with PDAC beyond the other inflammation-based prognostic index.

Limitations of this study include its retrospective analysis with potential biases, and the fact that all borderline cases underwent surgery and therefore the influence of neoadjuvant therapy on platelet counts was not considered. By accumulating data prospectively, the benefit of neoadjuvant therapy before surgery for PDAC may be clarified by PAR.

\section{Conflicts of Interest}

All Authors have no conflicts of interest to declare in regard to this study.

\section{References}

1 Torre LA, Bray F, Siegel RL, Ferlay J, Lortet-Tieulent J and Jemal A: Global cancer statistics, 2012. CA Cancer J Clin 65(2): 87-108, 2015.

2 Oyasiji T and Ma WW: Novel adjuvant therapies for pancreatic adenocarcinoma. J Gastrointesti Oncol 6(4): 430-435, 2015.

3 Valsecchi ME, Diaz-Canton E, de la Vega M and Littman SJ: Recent treatment advances and novel therapies in pancreas cancer: a review. J Gastroint Cancer 45(2): 190-201, 2014.

4 Grivennikov SI, Greten FR and Karin M: Immunity, inflammation, and cancer. Cell 140(6): 883-899, 2010.

5 La Torre M, Nigri G, Cavallini M, Mercantini P, Ziparo V and Ramacciato G: The glasgow prognostic score as a predictor of survival in patients with potentially resectable pancreatic adenocarcinoma. Ann Surg Oncol 19(9): 2917-2923, 2012.

6 Jamieson NB, Mohamed M, Oien KA, Foulis AK, Dickson EJ, Imrie CW, Carter CR, McKay CJ and McMillan DC: The relationship between tumor inflammatory cell infiltrate and outcome in patients with pancreatic ductal adenocarcinoma. Ann Surg Oncol 19(11): 3581-3590, 2012.

7 Stotz M, Gerger A, Eisner F, Szkandera J, Loibner H, Ress AL, Kornprat P, AlZoughbi W, Seggewies FS, Lackner C, Stojakovic T, Samonigg H, Hoefler G and Pichler M: Increased neutrophillymphocyte ratio is a poor prognostic factor in patients with primary operable and inoperable pancreatic cancer. Br J Cancer 109(2): 416-421, 2013

8 Shirai Y, Shiba H, Sakamoto T, Horiuchi T, Haruki K, Fujiwara Y, Futagawa Y, Ohashi T and Yanaga K: Preoperative platelet to lymphocyte ratio predicts outcome of patients with pancreatic ductal adenocarcinoma after pancreatic resection. Surgery 158(2): 360-365, 2015.

9 Kanda M, Fujii T, Kodera Y, Nagai S, Takeda S and Nakao A: Nutritional predictors of postoperative outcome in pancreatic cancer. Br J Surgery 98(2): 268-274, 2011.
10 Haruki K, Shiba H, Shirai Y, Horiuchi T, Iwase R, Fujiwara Y, Furukawa $\mathrm{K}$, Misawa $\mathrm{T}$ and Yanaga $\mathrm{K}$ : The $\mathrm{C}$-reactive protein to albumin ratio predicts long-term outcomes in patients with pancreatic cancer after pancreatic resection. World J Surg 40(9): 2254-2260, 2016.

11 Ahmad J, Grimes N, Farid S and Morris-Stiff G: Inflammatory response related scoring systems in assessing the prognosis of patients with pancreatic ductal adenocarcinoma: a systematic review. HBPD Int 13(5): 474-481, 2014.

12 Sobin HL, Gospodarowicz KM and Wittekind C: TNM Classification of Malignant Tumors, 7th Edition. WileyBlackwell, 2009.

13 Mantovani A, Allavena P, Sica A and Balkwill F: Cancer-related inflammation. Nature 454(7203): 436-444, 2008.

14 Hussain SP and Harris CC: Inflammation and cancer: an ancient link with novel potentials. Int J Cancer 121(11): 2373-2380, 2007.

15 Ebrahimi B, Tucker SL, Li D, Abbruzzese JL and Kurzrock R: Cytokines in pancreatic carcinoma: correlation with phenotypic characteristics and prognosis. Cancer 101(12): 2727-2736, 2004.

16 Alexandrakis MG, Passam FH, Moschandrea IA, Christophoridou AV, Pappa CA, Coulocheri SA, and Kyriakou DS: Levels of serum cytokines and acute phase proteins in patients with essential and cancer-related thrombocytosis. Am J Clin Oncol 26(2): 135-140, 2003.

17 Goubran HA, Stakiw J, Radosevic M and Burnouf T: Platelets effects on tumor growth. Semin Oncol 41(3): 359-369, 2014.

18 Chen $M$ and Geng JG: P-selectin mediates adhesion of leukocytes, platelets, and cancer cells in inflammation, thrombosis, and cancer growth and metastasis. Archiv Immunol Thera Exp 54(2): 75-84, 2006.

19 Qi C, Li B, Guo S, Wei B, Shao C, Li J, Yang Y, Zhang Q, Li J, He X, Wang L and Zhang Y: P-Selectin-Mediated Adhesion between Platelets and Tumor Cells Promotes Intestinal Tumorigenesis in Apc(Min/+) Mice. Int J Biol Sci 11(6): 679$687,2015$.

20 Yuzawa S, Kano MR, Einama T and Nishihara H: PDGFRbeta expression in tumor stroma of pancreatic adenocarcinoma as a reliable prognostic marker. Med Oncol 29(4): 2824-2830, 2012.

21 Bellone G, Smirne C, Mauri FA, Tonel E, Carbone A, Buffolino A, Dughera L, Robecchi A, Pirisi M and Emanuelli G: Cytokine expression profile in human pancreatic carcinoma cells and in surgical specimens: implications for survival. Cancer Immunol Immunother 55(6): 684-698, 2006.

22 Lashinger LM, Harrison LM, Rasmussen AJ, Logsdon CD, Fischer SM, McArthur MJ and Hursting SD: Dietary energy balance modulation of Kras- and Ink4a/Arf+/--driven pancreatic cancer: the role of insulin-like growth factor-I. Cancer Prev Res 6(10): 1046-1055, 2013.

23 Nixon AB, Pang H, Starr MD, Friedman PN, Bertagnolli MM, Kindler HL, Goldberg RM, Venook AP and Hurwitz HI: Prognostic and predictive blood-based biomarkers in patients with advanced pancreatic cancer: results from CALGB80303 (Alliance). Clin Cancer Res 19(24): 6957-6966, 2013.

24 Amo L, Tamayo-Orbegozo E, Maruri N, Eguizabal C, Zenarruzabeitia O, Rinon M, Arrieta A, Santos S, Monge J, Vesga MA, Borrego F and Larrucea S: Involvement of platelettumor cell interaction in immune evasion. Potential role of podocalyxin-like protein 1. Front Oncol 4: 245, 2014. 
25 Kopp HG, Placke T and Salih HR: Platelet-derived transforming growth factor-beta down-regulates NKG2D thereby inhibiting natural killer cell antitumor reactivity. Cancer Res 69(19): 77757783, 2009.

26 Bauer S, Groh V, Wu J, Steinle A, Phillips JH, Lanier LL and Spies T: Activation of NK cells and T cells by NKG2D, a receptor for stress-inducible MICA. Science 285(5428): 727$729,1999$.

27 Wu J, Song Y, Bakker AB, Bauer S, Spies T, Lanier LL and Phillips JH: An activating immunoreceptor complex formed by NKG2D and DAP10. Science 285(5428): 730-732, 1999.

28 Qi CL, Wei B, Ye J, Yang Y, Li B, Zhang QQ, Li JC, He XD, Lan $\mathrm{T}$ and Wang LJ: P-selectin-mediated platelet adhesion promotes the metastasis of murine melanoma cells. PloS one 9(3): e91320, 2014
29 Gupta D and Lis CG: Pretreatment serum albumin as a predictor of cancer survival: a systematic review of the epidemiological literature. Nutr J 9: 69, 2010.

30 Lin MY, Liu WY, Tolan AM, Aboulian A, Petrie BA and Stabile BE: Preoperative serum albumin but not prealbumin is an excellent predictor of postoperative complications and mortality in patients with gastrointestinal cancer. Am Surg 77(10): 1286$1289,2011$.
Received December 3, 2016

Revised January 13, 2017

Accepted January 18, 2017 